\title{
Legal Protection of Tobacco Farmers in Indonesia
}

\author{
Agus Dono Wibawanto \\ Student of Doctor program in law faculty of Universitas 17 Agustus 1945 Surabaya, Indonesia \\ gusdoncentre@gmail.com
}

\begin{abstract}
Tobacco and processed tobacco products is not only being an important part in the culture of the Indonesian nation. But they are also natural biological resources which have contributed greatly to the prosperity and welfare of the Indonesian people. Basically entrepreneurs or farmers of the Tobacco Industry as a very strategic trading eye have a very big role on the country's economy and the household economy of the Indonesian people specifically tobacco farmers. The cigarette and tobacco industry is one of the national industries that is still quite strong to date, in addition to material contributions in the form of state revenue from excise and employment, this tobacco-based industry is recognized as being part of the Indonesian community. This industry involves directly or indirectly. Nicotine in cigarettes is a group of legal addictive substances such as cigarettes, cigars, nicotine pieces which are stimulants, which increase dopamine and adrenaline. The main research question in this research is how is legal protection for tobacco farmers in the perspective of the Law of the Republic of Indonesia Number 36 of 2009 concerning Health? The research method used is normative legal research, using analysis of various legal materials. By using normative legal research methods because to produce new arguments, theories or concepts as a prescription in solving the problems faced, namely Legal Protection against Tobacco Farmers. The conclusions of this study are efforts to protect against the dangers of smoking, among others, by raising the price of cigarettes, prohibiting the sale of cigarettes to children less than 18 years and prohibiting the sale of cigarette bars and not ratifying the Framework Convention on Tobaco Control (FCTC).
\end{abstract}

Keywords: Ratio legis; legal protection; tobacco farmers; addictive substances.

\section{Introduction}

The Indonesian tobacco industry especially in East Java is an industry that has been officially designated by the Indonesian government as one of the national priority industries since 2008. Tobacco has a very important position in the plantation crop map, throughout the world is no exception cultivated diverse almost throughout Indonesia and especially in Java East. Tobacco is used to make cigarettes, along with cloves have made clove cigarettes. ${ }^{1}$

The cigarette and tobacco industry is one of the national industries that are still quite strong to date, in addition to material contributions in the form of state revenue from excise and employment, ${ }^{2}$ this tobacco-based industry is recognized as being part of the Indonesian community. ${ }^{3}$ This industry involves directly or indirectly up to 6.1 million people.

In accordance with Article 27 paragraph (2) of the 1945 Constitution of the Republic of Indonesia, which stated "Every citizen has a right to work and a decent living for humanity". The purpose of the sound of article 27 paragraph 2 in the Constitution 1945 is every Indonesian citizen entitled to get a decent job. Working that is in accordance with his

\footnotetext{
${ }^{1}$ Nabilla Al-Sadat et al., "Adolescent Tobacco Use and Health in Southeast Asia," Asia-Pacific Journal of Public Health 22, no. SUPPL. 3 (2010).

${ }^{2}$ Le Thi Thanh Huong et al., "Exposure to Tobacco Advertising, Promotion Among the Adult Population in Vietnam and Its Implications for Public Health," Asia-Pacific Journal of Public Health 29, no. 7 (2017): 569579.

${ }^{3}$ Finance.detik.com/ menperin: industri rokok libatkan tenaga kerja 61-jutaorang
} 
expertise and interests and not the work that is forced upon him. After getting a job an Indonesian citizen is also entitled to get a decent living. Worthy here is a decent livelihood for humans.

In addition, it is also protected by the provisions of Article 28A paragraph (2) of the 1945 Constitution which mandates, "Every person has the right to live and defend his life and life". Then the provisions of Article 28D paragraph (2) emphasize, "Every person has the right to work and to receive fair and appropriate remuneration and treatment in an employment relationship." Then this provision implies that everyone including tobacco farmers, the cigarette industry and their workforce as well as the owner of the company has the right to work and receive compensation and fair and just treatment for life. ${ }^{4}$

This condition is strengthened in Article 1 paragraph (3) Government Regulation of the Republic of Indonesia Number 31 Year 2009 Concerning the Protection of Geographical Areas that Produce Specific Location Plantation Products states that "Plantation products are products produced from plantations both cultivation and processing". In Article 3 of paragraph (1) that "site-specific plantation products that are protected for their sustainability are produced from coffee, tobacco, cinnamon, pepper, cocoa, and tea plants".

Law Number 39 of 1999 concerning Human Rights as well as Article 2 of the International Covenant on Civil and Political Rights (International Covenant on Civil and Political Rights); therefore it should not discriminate between the tobacco farmers and all those involved with regard to tobacco production with coffee, tea, wine, and so on. The Court is of the opinion that the substances contained in cigarettes can be detrimental to health but the content of these substances is not equivalent to the content of other addictive substances such as morphine, opium, cannabis, and the like (vide Constitutional Court Decision Number 6 / PUU-VII / 2009, p 278).

The controversy over the verses about tobacco clearly proves that the norm is not based on a deep academic text, so it does not provide fair legal certainty and regulates smoking. Why other products that contain addictive substances that are detrimental to health are not required to include health warnings. ${ }^{5}$ There must be a comprehensive solution regarding the regulation of addictive substances so that the regulation of addictive substances does not merely regulate tobacco.

\section{Research Methods}

This research is a legal research in which legal research to find solutions to legal issues that arise, while the results to be achieved is to provide a prescription of what should be. The type of legal research used is normative legal research. The reason researchers use normative legal research is because to produce new arguments, theories or concepts as a prescription in resolving the problems faced, namely Legal Protection against Tobacco Farmers in Perspective of Law of the Republic of Indonesia Number 36 Year 2009 Concerning Health.

\footnotetext{
${ }^{4}$ J. Henry Richardson, "Indonesian Labor Relations in Their Political Setting," Industrial and Labor Relations Review 12, no. 1 (1958): 56.

5 Serena Tonstad et al., "Adult Tobacco Cessation in Cambodia: I. Determinants of Quitting Tobacco Use.," Asia-Pacific journal of public health / Asia-Pacific Academic Consortium for Public Health 25, no. 5 Suppl (2013): 10-19.
} 
Normative legal research is used in the legislative approach because what will be examined are various legal regulations in the field of "Legal Protection of Tobacco Farmers in the Perspective of the Law of the Republic of Indonesia Number 36 Year 2009 on Health" in line with Peter Mahmud Marzuki's opinion that the "legislative approach will be carried out by examining all laws and regulations relating to the legal issues being addressed". 6

\section{Discussion}

\subsection{Farmers and Tobacco Contributions}

The contribution of tobacco itself absorbs a lot of labor because the jobs created from the tobacco sector and the tobacco products industry consisted of tobacco farmers, cigarette factory workers, cigarette traders, to street vendors and cigarettes themselves have a very large role in contributing to the National Budget (Revenue Budget) and State Expenditures). ${ }^{7}$

In terms of labor absorption, both directly and indirectly, in 2008 the tobacco products industry was able to absorb as many as 6.1 million workers. The FCTC (Framework Convention on Tobacco Control) was officially established as the first international agreement under WHO in the field of public health on May 21, 2003. The FCTC was subsequently signed on June 16-22, 2003 in Geneva and in June 2003-2004 in New York by the state countries who are willing to adopt the contents of the FCTC as a form of political commitment. Countries that still want to sign the FCTC after 2004 through a process (accession) that is equivalent to ratification.

In February 2005 the FCTC was officially put in place. Because it has been signed by more than 40 countries, the FCTC becomes a convention under international law related to tobacco control that is binding on the countries that ratify it. ${ }^{8}$

Satjipto Rahardjo defines that: Political law as an activity of choosing and ways to be used to achieve a certain social and legal goals in society". ${ }^{9}$

Indonesia has become the target of the foreign cigarette industry due to weak tobacco control regulations. Indonesia, for example, has not yet ratified the Frame Convention Tobacco Control (FCTC). China and India have ratified the rule. Indonesia, whose market is much bigger than the two countries, has not yet done so. Indonesia is the fifth largest country in the world cigarette market. Because Indonesia has not yet ratified the tobacco control rules, foreigners have the opportunity to invade. Economically, the Indonesian market is lucrative previously Philip Morris and BAT targeted China. However, China hurriedly ratified international tobacco control rules so they turned to Indonesia. Foreign investors chose Indonesia because the health protection regulations from cigarettes are very weak and the consumption of cigarettes in Indonesia is quite large, ${ }^{10}$ as stated in the interview excerpt below: "This shows the attractive Indonesian Cigarette Market for Foreign Parties so that they invite them to acquire large cigarette manufacturers in Indonesia.

\footnotetext{
${ }^{6}$ Ibid., p. 89.

${ }^{7}$ Justus M. van der Kroef, “Indonesia’s Economic Difficulties,” International Journal 17, no. 4 (1962): 399.

${ }^{8}$ Melinda J. Ickes et al., "Support for Tobacco 21 in a Tobacco-Growing State," Western Journal of Nursing Research 41, no. 8 (2019): 1203-1215.

${ }^{9}$ Satjipto Raharjo,, Ilmu Hukum, Bandung: 2000. Citra Aditya Bakti, p.:35.

${ }^{10}$ Israel T. Agaku and Olalekan A. Ayo-Yusuf, "The Effect of Exposure to Pro-Tobacco Advertising on Experimentation With Emerging Tobacco Products Among U.S. Adolescents," Health Education and Behavior 41, no. 3 (2014): 275-280.
} 


\subsection{Cigarettes and Poverty Conditions}

In Indonesia, in the city and in the hamlet, smokers can easily be witnessed, from elementary school age to old farts, so it is fun to enjoy the nicotine poison. Nicotine in English means "toxic alcohol contained in tobacco. "Smoker's character that does not bother with the environment, and the cigarette smoke still steaming. On a bus loaded with passengers, on trains, in public places, this suction expert had no burden whatsoever to demonstrate his expertise in drinking the poison. The suffering of others who sit next to him is hardly considered. As such, smokers are selfish in their perfect format.

The egoism of smokers can have far-reaching destructive effects on their offspring. ${ }^{11}$ Included in this category are buskers roaming at red-light intersections in cities. While he is singing but cigarettes were not separated from his mouth. There is no awareness and shame here, the results of the singing is also to be burned, no matter the day of the fasting month. Thus is the feeling of some humans.

Try to observe the panorama below. In Saudi Arabia, there is a smoking ban forbidding. In various public spaces this warning reads: "al-tadkhin mamnu 'or mamnu' al-tadkhin (haram smoking). But what applies in reality? Of the approximately 23 million inhabitants of the kingdom, six million are heavy smoking addicts in every year. ${ }^{12}$ No less than 12 billion riyals (around Rp.28.8 trillion) were spent by addicts every year, if only they had halved the character, Rp14.4 trillion of funds would be available to empower the poor in Indonesia, for example. According to Syariah in here, smoking is illicit goods.

\subsection{Tobacco Impact Control}

Activists accuse the tobacco industry of riding on farmers' rejection of efforts to mitigate the impact of tobacco. ${ }^{13}$ Farmers demonstrate, perhaps it is no longer strange in a country that respects freedom of expression. Only a question, is it true that their interests are disturbed so that triggered the action.

The question stopped in the minds of tobacco impact control activists, at a press conference in Jakarta, Thursday (30/9). Activists who are members of the Tobbaco Control Support Center (TCSC) suspect there are other parties who are riding the action. As is known, hundreds of tobacco farmers who are members of the Indonesian Tobacco Farmers Association (APTI) rallied on Wednesday (29/9). Decisively, they rejected the latest recommendations issued by the Framework Convention on Tobacco Control (Framework Convention on Tobacco Control World Health Organization / FCTC WHO). Namely, articles 9 and 10 concerning the prohibition of using other materials besides tobacco leaves in tobacco products.

APTI Chairman of the National Leadership Board Abdus Setiawan stressed, if implemented it would destroy the source of income of millions of Indonesian tobacco and clove farmers. "In addition, it can also threaten the sustainability of the national kretek

\footnotetext{
11 Leonard A. Jason et al., "Youth Caught in Violation of Tobacco Purchase, Use, and Possession Laws: Education versus Fines," Behavior Modification 31, no. 6 (2007): 713-731.

${ }^{12}$ See Padang Express, 9 April 2007, page 5.

${ }^{13}$ Simon Barraclough and Martha Morrow, "The Political Economy of Tobacco and Poverty Alleviation in Southeast Asia: Contradictions in the Role of the State.," Global health promotion 17, no. 1 Suppl (2010): 4050 .
} 
industry," he said. He estimates that in Indonesia, the recommendation could result in two million tobacco farmers and 1.5 million clove farmers losing their livelihoods.

Farmers' concern was shown by Deputy Minister of Agriculture (Wamentan) Bayu Krisnamurthi at the action. He said, according to Law No. 12 of 1992 concerning Plant Culture Systems, farmers were freed to plant the crops they wanted. Similar concerns were echoed by them when the Ministry of Health spawned RPP on Safeguarding Tobacco Products as Addictive Substances for Health. They even rejected the Tobacco Product Impact Control Bill.

The two regulations are in harmony, which is implementing a fiscal policy with a large value to reduce cigarette consumption. TCSC activists deplored the action. "Farmers' concerns are not reasonable enough because the FCTC will not interfere with their welfare," said one activist Kartono Mohammad at a press conference on Thursday (30/9). He mentioned, Articles 9 and 10 of the FCTC require that the cigarette industry must openly disclose to the government, that there are around 600 dangerous addictive substances in cigarettes. "Only the producers must submit health information that must be known by the government. There is no connection with farmers, "continued the former Chair of the Indonesian Doctors Association.

\subsection{Farmers Legal Protection Efforts}

Tobacco taxes are the most effective way to reduce tobacco use. But only 21 countries have tobacco tax rates greater than 75 percent of retail prices. The first protocol of the Convention aimed at combating illicit tobacco trade is being negotiated, that the tobacco industry describes itself as responsible and asks to be part of the negotiations. The Fifty-third World Health Assembly, Recalling and reaffirming resolution WHA52.18 established by both intergovernmental negotiating bodies to design and negotiate WHO's proposed framework convention on tobacco control and protocols related to a working group to prepare the proposed draft elements of the convention framework and report progress; After considering the report to the Health Assembly at the convention framework for tobacco control, on the prevention of infectious diseases and controls ask the Director General to formulate a global strategy for the prevention and control of non-communicable diseases and submit the proposed global strategy and implementation plan to the Executive Board and the Health Assembly Realizing human suffering the very large are caused by non-communicable diseases such as heart disease, cancer, diabetes and chronic respiratory diseases, and the threat they pose to the economies of many member countries, which causes health disparities to increase between countries and populations.

Noting that conditions in which people live and their lifestyles affect health and quality of life, and that non-communicable diseases are most prominent related to common risk factors, namely, tobacco use, alcohol abuse, unhealthy diet, physical activity, environmental carcinogens, and being aware of that economic, social, gender, political, behavioral and environmental risk factors; Reaffirming that the global strategy for the prevention and control of non-communicable diseases and subsequent implementation plans are directed at reducing early death and improving quality of life; Recognizing the role of leadership that WHO must play in promoting global action against non-communicable diseases, and WHO's contribution to global health is based on advantages compared to other organizations

A report on tobacco product pricing and taxation policies was discussed and the delegation agreed to form a working group tasked with further examining the problem and, if 
possible, preparing guidelines for implementation. The convention party also decided that working on sustainable economic alternatives for tobacco growth would be expanded in order to find the right policy choices and recommendations. Negotiations on a protocol to combat the illegal trade in tobacco products must continue with the aim of concluding in 2012, it was decided.

The delegation also adopted a decision to promote the implementation of treaty 'and strengthen assistance to developing countries to fulfill their obligations under the convention. They also decided that further work was needed on the control and prevention of smokeless tobacco products and electronic cigarette obligations in connection with the health effects of tobacco consumption and cross-border advertising. Tobacco use is considered a global epidemic by all member countries of the World Health Organization.

Nearly 5 million people die from tobacco-related diseases each year, and if this trend continues, by 2030 around twice this number is projected to be destroyed every year from the disease. In response to this crisis, countries around the world have pledged their support for the United Nations Framework Convention on Tobacco Control (FCTC), which took effect on February 28, 2005. That day, the agreement made history by becoming a legally binding agreement on health first the international community.

By ratifying the United Nations Framework Convention on Tobacco Control, the US can show the global community that it cares about the public health of its citizens, and people around the world. The FCTC, one of the fastest ratified treaties in UN history, is a supranational agreement that seeks to protect present and future generations from damaging health, social, environmental and economic consequences of tobacco consumption and exposure to tobacco smoke by adopting a set of universal standards that state the dangers of tobacco and limit their use in all forms throughout the world. For this purpose, the terms of the agreement include rules governing the production, sale, distribution, advertising and taxation of tobacco. FCTC standards, however, are minimum requirements, and signatories are encouraged to be more stringent in regulating tobacco than the agreement requires them to be. FCTC is a moment for international public health, not only the agreement that was first adopted under WHO Article 19, but also marks one of the first multilateral, binding agreements regarding chronic, non-communicable diseases. The FCTC is next when the watershed for the European Union.

WHO has long been active in preventing various health problems resulting from tobacco of consumption. As a leading cause of preventable global death, tobacco has seen the resurgence in both consumption and mortality rates throughout the world with the link to the increasing global economy. Thus, while disease-related tobacco is different from infectious diseases that have traditionally been a concern of WHO, the impact of globalization has made tobacco more relevant to the intergovernmental authority.

Article 5.3 Requests for reducing taxes and other measures to reduce the demand for cigarettes. Article $6 \& 7$ is Passive smoking Obligation to protect all people from exposure to cigarette smoke in the workplace of the room, public transportation and public places in the room. Article 8 Regulations on the contents and emissions of tobacco products must be regulated and ingredients must be disclosed. Article 10 Large packaging and labeling of health warnings (at least $30 \%$ of the package cover, $50 \%$ or more recommended); Deceptive labels ("light", "light", etc.) are prohibited. The Article $9 \& 11$ is awareness Public awareness of the consequences of smoking. Article 12 is tobacco advertising Comprehensive prohibition, unless the national constitution prohibits it. The article 13 is Addiction and 
termination program. Article 14 Smuggling Measures necessary to eliminate illegal trade in tobacco products. The article 15 is children Limited sales for minors.

Article 16 Research Related to research tobacco and information sharing among parties. Articles 20, 21, \& 22 The FCTC established two main bodies to oversee the function of the agreement: the Conference of the Parties and the permanent Secretariat. In addition, there are more than 50 different intergovernmental and non-governmental organizations that are official observers for the Conference of the Parties.

According to Nikogosian, ${ }^{14}$ is most parties have passed or renewed and strengthened national legislation and policies to fulfill their obligations under the agreement. A 2010 update on the progress of FCTC implementation reported that $80 \%$ of Parties currently facilitate public information and / or educational programs about the dangers of tobacco, in addition to limiting the consumption of underage tobacco through laws that prohibit retailers from selling tobacco products to minors. Furthermore, $70 \%$ of Parties have made large, clear and visible health warnings mandatory for tobacco packaging. However Nikogosian warned that the agreement was only a "tool", and that the company depended on how effectively the Parties implementing the guidelines set it.

The opiate effect created and causing chronic dependence seems to negate all aspects of the externality of smoking. Then, when an institution called the Indonesian Parliament Forum (Law Parliament) spawned a Bill on Tobacco Impact Management (call it the Tobacco Bill) for health, many parties had beard fires, especially smoking industry circles. Like the style of football, the cigarette industry uses a total football stance to annul this bill, including buying scientists from the most famous universities in the country. This bill has pocketed the support of 224 members of the House of Representatives (40.7 percent) and is being urged to penetrate the National Legislation Program (Prolegnas) through the entrance of the Legislative Body of the DPR. It is questionable, on what consideration, so that this Bill should be immediately discussed and passed. It's not too difficult to justify it. ${ }^{15}$

First, health and social interests. The excess of the externality of tobacco with all its derivatives is final. A cigarette contains 4,000 dangerous chemical poisons, 10 of which are carcinogenic. Negative excess does not only affect health, but also social, economic, moral, and cultural excesses. Research by Rita Damayanti (lecturer at the Faculty of Public Health, University of Indonesia, 2006) proves smoking behavior contributes significantly to the growth of various social ills, such as narcotics use, violence, even HIV / AIDS. Cigarette smoke against students is now very worrying, at least according to the WHO's 2006 Global Youth Tobacco Survey, which is 37.3 percent of male and female students in Indonesia including smoking and 24.5 percent of male students have even became an active smoker. Meanwhile, according to the analysis of Soewarta Kosen (Health Research and Development Economist at the Ministry of Health), the total productive years lost due to tobacco-related diseases in Indonesia in 2005 were 5,411,904 Disability Adjusted Life Years (DALYs). If calculated with annual income per capita in 2005 of US \$ 900, total lost costs were US \$ $4,870,713,600 .{ }^{16}$

\footnotetext{
${ }^{14}$ Nikogosian, Head of WHO FCTC Secretariat. INAL PROGRAMME www. Who. int/.../fctc/Final_Programme_EN.

${ }^{15}$ Urgensi Rancangan Undang-Undang Tembakau - Indonesian ...indotc1 .blogspot. Com/2007/.../urgensirancangan-undang-undang.ht... 27 Mei 2007.

${ }^{16}$ Soewarta Kosen,Rokok tidak bagus tuk kita rokoktidakbagustukkita. blogspot.com/15 Apr 2009 - 2007.
} 
Second, when the social, economic, and health impacts of smoking are so severe, ironically, until this moment we do not yet have a legal product that comprehensively regulates the smoking industry. However the cigarette industry is an industry that produces and markets problematic goods. At present the problem of the dangers of smoking is only regulated by Government Regulation No. 19 of 2003 concerning the Prevention of Cigarette Danger for Health, which is a descendant of Article 44 of the Law on Health. However, the fact is, this PP is not able to peck anyone who violates it, including violations of cigarette ad serving hours by the mass media. Historically political, the PP discussion process was precisely dictated by the tobacco industry.

Third, the constellation of international politics is. The Tobacco Impact Draft Bill is urgent since the Indonesian government has become an object of ridicule by the international community, especially by WHO member countries and the community's non-governmental organizations. The Indonesian government was even given an award called the ashtray award, aka the nicotine waste basket country. All this happened because the Indonesian government did not sign / ratify the convention named FCTC. The Indonesian government's rejection of the FCTC is a denial of international commitments, because the Indonesian delegation was actively involved in discussing the draft FCTC (as a drafting committee member). The Indonesian delegation also unanimously accepted the substance of the FCTC in the World Health Assembly in Geneva, Switzerland, May 2003.

Now the FCTC has become international law and 137 countries have ratified it. Then why is the cigarette industry and its close cronies so serious about conquering the Legislative Body of the House of Representatives so that they do not include this bill in the National Legislation Program. Will their existence be displaced.

\section{Conclusion}

A regulation should cover the economic, social, political, cultural, health and sustainability of tobacco farmers. Legal protection for tobacco farmers in the perspective of the Republic of Indonesia Law number 36 of 2009 concerning health. In contrast to products that have other negative and dangerous effects, the regulation of tobacco products (cigarettes) continues to cause controversy in the community. The negative impact of cigarettes on health, the community's economy, social and the environment does not need to be debated anymore, but the fact that the tobacco product industry has made a major contribution through excise revenue and the employment sector is also recognized by the Government and this reason is also always the reason for the Government of the Republic of Indonesia (RI) to protect the tobacco product industry from all forms of regulation. Tobacco farmers have not yet enjoyed the welfare level which is equivalent to the surge in cigarette production and industrial profits. Prior to the issuance of regulations issued to limit the productivity of tobacco farmers, the government should facilitate farmers to switch to other agricultural commodities with more profitable results. The approach can be carried out by conducting research first if there are research results that show two out of three farmers and farm laborers want to switch businesses, then the policy towards the regulation can be enforced.

\section{References}


Agaku, I., T., and Olalekan A. (2014). Ayo-Yusuf. "The Effect of Exposure to Pro-Tobacco Advertising on Experimentation With Emerging Tobacco Products Among U.S. Adolescents." Health Education and Behavior, 275-280.

Al-Sadat, N., Misau, A. Y., Zarihah, Z., Dahlui Maznah, and Tin Tin Su. (2010). "Adolescent Tobacco Use and Health in Southeast Asia." Asia-Pacific Journal of Public Health 22, no. SUPPL. 3.

Barraclough, Simon, and Martha Morrow. (2010). "The Political Economy of Tobacco and Poverty Alleviation in Southeast Asia: Contradictions in the Role of the State." Global health promotion 17, no. 1 Suppl: 40-50.

Huong, Le Thi Thanh, Tran Khanh Long, Tran Thi Van Anh, Tran Thi Tuyet-Hanh, Kim Bao Giang, Phan Thi Hai, Doan Thu Huyen, et al. (2017) "Exposure to Tobacco Advertising, Promotion Among the Adult Population in Vietnam and Its Implications for Public Health.” Asia-Pacific Journal of Public Health 29, no. 7: 569-579.

Ickes, Melinda J., Karen Butler, Amanda T. Wiggins, Mary Kay Rayens, and Ellen J. Hahn. (2019). "Support for Tobacco 21 in a Tobacco-Growing State." Western Journal of Nursing Research 41, no. 8: 1203-1215.

Jason, Leonard A., Steven B. Pokorny, Monica Adams, Yvonne Hunt, Praveena Gadiraju, Taylor Morello, Michael Schoeny, and Crystal Dinwiddie. (2007). "Youth Caught in Violation of Tobacco Purchase, Use, and Possession Laws: Education versus Fines." Behavior Modification 31, no. 6: 713-731.

Kroef, Justus M. van der. (1962). “Indonesia's Economic Difficulties.” International Journal 17, no. 4: 399.

Ministry, Japanese, and Project Manager. (1999). "Health-Making Difference".

Richardson, J. Henry. (1958) "Indonesian Labor Relations in Their Political Setting." Industrial and Labor Relations Review 12, no. 1: 56.

Tonstad, Serena, Jayakaran S. Job, Michael Batech, Daravuth Yel, They Kheam, and Pramil N. Singh. (2013). "Adult Tobacco Cessation in Cambodia: I. Determinants of Quitting Tobacco Use." Asia-Pacific journal of public health / Asia-Pacific Academic Consortium for Public Health 25, no. 5 Suppl: 10-19.

Woodhouse, Lynn D., Judith J. Sayre, and William C. Livingood. (2001) "Tobacco Policy and the Role of Law Enforcement in Prevention: The Value of Understanding Context." Qualitative Health Research 11, no. 5: 682-692. 